\section{$\underset{\substack{\text { hommes } \\ \text { \& migrations }}}{ }$}

\section{Hommes \& migrations}

Revue française de référence sur les dynamiques

migratoires

1323 | 2018

Persona grata

\title{
Babels, De Lesbos à Calais : Comment l'Europe fabrique des camps
}

Lyon, Le Passager clandestin, coll. « Bibliothèque des frontières », 2017, 130 pages, $10 €$

\section{Apolline Meyer}

\section{(2) OpenEdition}

1 Journals

\section{Édition électronique}

URL : https://journals.openedition.org/hommesmigrations/7939

DOI : 10.4000/hommesmigrations.7939

ISSN : 2262-3353

Éditeur

Musée national de l'histoire de l'immigration

\section{Édition imprimée}

Date de publication : 1 octobre 2018

Pagination : 215-216

ISBN : 978-2-919040-42-1

ISSN : 1142-852X

Référence électronique

Apolline Meyer, «Babels, De Lesbos à Calais : Comment l'Europe fabrique des camps », Hommes \& migrations [En ligne], 1323 | 2018, mis en ligne le 01 octobre 2018, consulté le 08 janvier 2022. URL http://journals.openedition.org/hommesmigrations/7939; DOI : https://doi.org/10.4000/ hommesmigrations.7939 


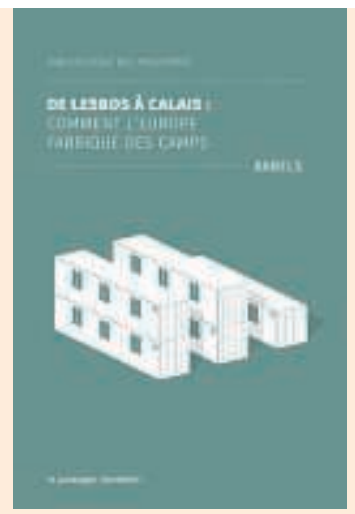

abords des frontières de l'Europe et aux carrefours des grandes routes migratoires, qui deviennent des espaces de relégation et de mise en attente. Comprendre la formation, le fonctionnement de ces camps, et ce qu'ils produisent sur leurs occupants et les sociétés dans lesquels ils s'insèrent, tel est l'objectif de cet ouvrage, qui interroge les contradictions des politiques migratoires européennes pour déconstruire le diagnostic de «crise». L'ouvrage questionne la responsabilité politique des États de l'Union européenne dans le processus d'encampement des populations migrantes: "L'Europe, plutôt qu'elle n'a subi une situation incontrôlée, a «fabriqué» des camps: par les fermetures des frontières, par l'inorganisation de l'accueil, par la rupture de solidarité entre les États, pourtant soumis aux mêmes règles et aux mêmes obligations de protection des

\section{Babels, De Lesbos} à Calais : Comment l'Europe fabrique des camps

Lyon, Le Passager clandestin, coll. «Bibliothèque des frontières », 2017, 130 pages, $10 €$.

Depuis la fin 2014, la multiplication des camps de migrants apparaît comme le signe le plus évident de la «crise des réfugiés», comme en témoigne l'ultra-médiatisation du démantèlement de ladite «jungle» de Calais. Symptôme de la crise autant que modalité de gestion de celle-ci par les pouvoirs publics, ces camps se développent aux réfugiés. » Cette responsabilité peut être directe, lorsque les pouvoirs publics créent des camps pour contrôler les déplacements des migrants: les hotspots, mis en place à partir d'octobre 2015 par l'UE dans les principaux lieux de transit (îles grecques et italiennes), permettent ainsi de procéder à l'identification, à l'enregistrement et au tri des migrants. Mais l'absence de politique d'accueil coordonnée favorise également le développement de camps de fortune près des lieux-frontières où le passage est empêché, comme ce fut le cas notamment à Idomeni, ville du nord de la Grèce, après la fermeture de la frontière macédonienne en 
mars 2016. Le terme de «camp» recouvre donc une grande diversité de réalités, plus ou moins précaires, plus ou moins officielles. Pour penser à la fois l'hétérogénéité et la continuité de ces espaces investis de gré ou de force par les populations migrantes, Michel Agier utilise le concept de "forme camp», caractérisée par «l'extraterritorialité, l'exception et l'exclusion», à des degrés divers. D'un côté du spectre, on trouve des campements informels, auto ou cogérés par des associations, qui échappent en partie au contrôle étatique et peuvent ainsi devenir «le lieu de cristallisation d'actions solidaires, de politisation ", comme à Calais; de l'autre, des centres officiels comme les Centres de rétention administrative (CRA) où la logique répressive ne cesse de se renforcer. L'expérience de l'encampement est donc radicalement différente selon l'objectif du camp, sa vocation à être durable ou non, et son mode de gouvernance - paramètres qui peuvent d'ailleurs évoluer au cours du temps. Pour finir, les auteurs constatent l'essor d'un «marché » de l'enfermement des étrangers, qui s'explique par un recourt massif à la sous-traitance au sein des camps et des centres officiels. Outre les risques induits par la logique de rentabilité sur la qualité des prestations, la privatisation (même partielle) des dispositifs d'enfermement conduit à leur dépolitisation, car leur dimension coercitive se voit édulcorée par une rhétorique quasi «hôtelière». L'ouvrage alerte ainsi sur les risques de désengagement et de déresponsabilisation des États sur un enjeu aussi crucial que l'accueil des migrants, alors que le marché de la sécurisation des frontières européennes pourrait atteindre les 29 milliards d'euros en 2022 (Selon une étude de l'ONG Transnational Institute), rendant de plus en plus palpable l'influence des intérêts économiques dans l'édiction des politiques migratoires européennes. Apolline Meyer 